\title{
Germanica
}

\section{Zwischen Kaiserpanorama und Passage du panorama Walter Benjamins medienästhetische Reflexionen als « Schwellenkunde »}

Entre Kaiserpanorama et Passage du Panorama : esthétique médiatique et connaissance dans la topographie des seuils et des passages chez Walter Benjamin.

\section{André Combes}

\section{(2) OpenEdition}

Journals

Édition électronique

URL : http://journals.openedition.org/germanica/1803

DOI : $10.4000 /$ germanica. 1803

ISSN : 2107-0784

Éditeur

Université de Lille

\section{Édition imprimée}

Date de publication : 30 juin 2004

Pagination : 37-59

ISBN : 9782913857131

ISSN : 0984-2632

Référence électronique

André Combes, «Zwischen Kaiserpanorama und Passage du panorama Walter Benjamins medienästhetische Reflexionen als « Schwellenkunde » », Germanica [Online], 34 | 2004, Online erschienen am: 12 Oktober 2012, abgerufen am 06 Oktober 2020. URL : http://

journals.openedition.org/germanica/1803; DOI : https://doi.org/10.4000/germanica.1803

Ce document a été généré automatiquement le 6 octobre 2020.

(c) Tous droits réservés 


\title{
Zwischen Kaiserpanorama und Passage du panorama Walter Benjamins medienästhetische Reflexionen als «Schwellenkunde » ${ }^{1}$
}

\author{
Entre Kaiserpanorama et Passage du Panorama : esthétique médiatique et \\ connaissance dans la topographie des seuils et des passages chez Walter
}

Benjamin.

André Combes

\begin{abstract}
Von Benjamins zeitweise intensiver Beschäftigung mit der Photo- und Filmproblematik zeugen Titel wie Kleine Geschichte der Photographie, Das Kunstwerk im Zeitalter seiner technischen Reproduzierbarkeit oder die beiden weniger bekannten Pariser Briefe ${ }^{2}$. Aber diese Texte stellen lediglich den ausformulierten Teil einer im ganzen Werk verstreuten Problematik des Visuellen dar, die sich nicht nur in vielschichtigen Begriffen niedergeschlagen (man denke nur an den Begriff der « Aura »), sondern bis in Motiv- und Themenkonstellationen, Allegorien und Metaphern, Spuren hinterlassen hat. Nimmt man z.B. Benjamins Fragment gebliebenes Hauptwerk, die 1927 begonnene Arbeit über die Pariser Passagen, so wird man diesem vielleicht am besten gerecht, wenn man die visuellen Aspekte (Blick und Blickbewegung, optisch erfahrene Elemente der Hauptstadttopographie, Beleuchtungsarten etc.) nicht als Konglomerat von losen Reflexionen und bunt zusammengewürfelten Wahrnehmungsnotaten, sondern als Momente einer «Dialektik des Sehens » auffaßt ${ }^{3}$, so daß diese Reflexionen als visuelle Dispositive des Denkens angesehen werden können. In einer solchen Dialektik werden die reale und die imaginäre Dimension des Wahrgenommenen in einen gesamtgesellschaftlichen "Ausdruckszusammenhang ${ }^{4}$ einbezogen, der es möglich macht, die empirische «Physiognomie » der Dingwelt zu begrifflichen Signifikationen $\mathrm{zu}$ verarbeiten, die sich wiederum in Gestalt von Bildern («dialektischen Bildern ») präsentieren. Bezeichnenderweise beschreibt einer der Herausgeber von Benjamins Gesammelten Schriften das Verfahren mit Hilfe einer photographischen Metaphorik :
\end{abstract}


Wie ein Stück Landschaft, in der ein photographischer Apparat aufgestellt wurde, hinter den der Operateur weit und lange zurücktritt, wandert das Ding durch das tote, groß geöffnete und durch kein Blinzeln bewegte Auge [...] in die camera obscura ein, die das Objekt erst dem hingegebenen Studium überliefert ${ }^{5}$.

Dies gilt auch für zahlreiche andere Texte, die sich, wie die im Ursprung des deutschen Trauerspiels analysierte barocke Allegorie, der gedanklichen « Errettung der physischen Realität » (Kracauer) ${ }^{6}$, nicht zuletzt der vergangenen, verschrieben haben. Es gilt für viele « Denkbilder » und Textbausteine aus Einbahnstraße oder Berliner Kindheit um 1900, in denen die von Benjamin geschätzte Goethesche «zarte Empirie » ständig Anlaß zu «Extrapolationen im Kleinsten» (Adorno) gibt, die oft über die jeweilige Wahrnehmungssituation vermittelt werden.

3 Anhand von bestimmten Topoi des Passagen-Werks, das einige Modalitäten und Implikationen einer solchen « Dialektik des Sehens » erhellen, soll hier gezeigt werden, daß Benjamins «physiognomische » Reflexionen über die Haupt- und Weltstadt Paris großenteils von sinnlichen - insbesondere optischen - Erfahrungen geprägt sind, deren Beschreibung sich implizit an einer photographischen bzw. kinematographischen Problematik orientiert. Und dies nicht nur, weil auf geschichtsphilosophischer Metaebene diese Reflexionen eine Art Gedankenoptik initiieren, indem sie den Versuch unternehmen, im historischen «Zeitraffer» bzw. in der «Telescopage der Vergangenheit durch die Gegenwart ${ }^{7}$, das XIX. Jahrhundert vor dem Hintergrund der zwanziger und dreißiger Jahre des XX. zu durchleuchten, so daß, wie in Daguerres Dioramen, von denen noch die Rede sein wird, im Bild des XIX. Jahrhunderts durch einen Beleuchtungswechsel die Konturen des XX. sichtbar werden.

4 Denn der vielseitig geschulte Blick des flanierenden «Sammlers» und «Physiognomikers » Benjamin ${ }^{8}$ bietet die Gewähr, das zu lesen, « was nie geschrieben wurde », wie die von ihm gern zitierte Formel aus Hofmannstahls Der Tor und der Tod lautet. Im Paris des XIX. Jahrhunderts ist dies vor allem eine im Entstehen begriffene neue Seh- und Bewegungskultur'.

5 Eine solche Dechiffrierung, die im Gestus des «Aufsprengens » des Kontinuums des Sichtbaren an die "Kino-Dechiffrierung» eines Vertov erinnern mag, gilt den «Urphänomenen» der Moderne, wie den fast gleichzeitig entstandenen Pariser Passagen und Panoramen, den später aufgekommenen Warenhäusern und Weltausstellungen, die als « mythologische Topographien » (V.1, 139) sich zunächst ins Stadtbild eingeschrieben und dieses dabei um eine wesentliche mythische Dimension erweitert hatten. Darüber hinaus vermögen diese Topographien den Bewegungen der Körper und der Blicke, den taktilen und optischen Modalitäten des Gehens und des Sehens in der Großstadt ihr Gepräge aufzudrücken. Dabei macht Benjamins Lektüre deutlich, daß im Wahrnehmungshabitus einer vorkinematographischen Zeit spätere Merkmale der Kinematographie vorgezeichnet waren.

6 Wenn sich Benjamin aber in den eingangs erwähnten Texten ausdrücklich vornimmt, aus der Frühphase der technischen bzw. medientechnischen Reproduzierbarkeit deren Zukunft, wie sie sich zu seiner Zeit hauptsächlich im Film präsentiert ${ }^{10}$, herauszulesen, geschieht dies also im Gesamtkontext einer breit angelegten ideologiekritischen Analyse der Urgeschichte des XIX. Jahrhunderts, wie sie sich eben exemplarisch an dessen « Hauptstadt » Paris ablesen läßt. Im Mittelpunkt steht dabei das ganze Geflecht der wichtigsten Manifestationen der in diesem Jahrhundert sich allgemein durchsetzenden und um die «Königin Ware» inszenierten kapitalistischen 
Industriekultur. Wie die Frankfurter Schule es analysierte, war diese in der Hauptsache eine Kulturindustrie, d.h. auch eine Bewußtseins- und Wahrnehmungsindustrie.

Denn untersuchen wollte Benjamin in seiner Passagenarbeit den sich um 1850 in Frankreich rasant etablierenden «frühen Hochkapitalismus» (Adorno) in seinem vielfältigen "Ausdruckszusammenhang " mit den «Phantasmagorien der kapitalistischen Kultur », die die Warenproduktion mit einem mystifizierenden Schein umgeben und die sich u.a. in den Passagen als "Warentempeln », oder in den schnell aufkommenden Warenhäusern manifestierten, bevor sie « auf der Weltausstellung 1867 ihre strahlendste Entfaltung» erreichten (V.1, 51). So konnte sich in Benjamins gegenwartsgesteuerter Rückschau Paris deshalb als «Hauptstadt des XIX. Jahrhunderts » präsentieren, weil die "ville lumière » ihr Licht hauptsächlich daraus bezog, daß sie im Second Empire zur unumstrittenen «Kapitale des Luxus und der Moden» wurde. Der ganze phantasmagorische Bilderkomplex, dem Benjamin als «materialistischer Historiker» zur Lesbarkeit verhelfen wollte, nährt sich aus dem "bildschaffenden Unbewußten», das als "Traum- oder Wunschwelt» in den «bürgerlichen Vorstellungs- und Formenkanons des 19. Jahrhunderts» auf zweideutige Weise zum Ausdruck kommt ${ }^{11}$.

Im europäischen Schlaf, den man Kapitalismus nennt, träumen die Massen. Und die Bilder, die ihren Wunsch entstellend zum Ausdruck bringen, formieren sich zu Phantasmagorien. Verdichtung und Verschiebung sind die Werkmeister, Angst und Wunsch die Ausdrucksenergien des kollektiven Traums. Sein geträumtestes Objekt heißt Paris - Hauptstadt des 19. Jahrhunderts ${ }^{12}$.

Da Phantasmagorien als Produkte des kollektiven Imaginären bzw. der «camera obscura der Ideologie $»^{13}$ schon rein etymologisch eine unmittelbare Beziehung zur grundsätzlichen Unheimlichkeit des Bildes haben - als Raum eben, in dem sich Gespenster (Phantome und Phantasmen) herumtummeln -, wären sie für unsere Problematik von Interesse. Darauf soll aber hier nicht näher eingegangen werden, auch wenn wir im Folgenden dann und wann Phantasmagorisches berühren. Es sollen lediglich zwei "mythologische Topographien", wie Benjamin sie nennt, unter dem schon erwähnten Aspekt des dialektischen Ausdruckszusammenhangs zwischen dem Aufkommen einer von allerlei Phantasmagorien geprägten kapitalistischen Industriekultur und der Herausbildung eines neuen Wahrnehmungshabitus' analysiert werden: die Pariser Passagen und die Panoramen. An ihnen läßt sich Benjamins «Schwellenkunde», seine Vorliebe für die Übergänge zwischen Materiellem und Immateriellem, zwischen Visuellem und Gedanklichem sowie seine mikrologische Fähigkeit, « in der Analyse des kleinen Einzelmoments den Kristall des Totalgeschehens zu entdecken » (V.1, 575), in ihrer Vielgestaltigkeit besonders deutlich beobachten.

\section{Pariser Passagen}

Bevor Benjamin Paris zur «Hauptstadt des XIX. Jahrhunderts » machte und deren exemplarische Bedeutung für das Verständnis der Moderne herausarbeitete, hatte er seinen Blick eines «mythologischen Topographen» schon an Moskau (1926-27) und Neapel (1926) geschult. In Paris aber, das er 1927 zusammen mit seinem Freund Franz Hessel ${ }^{14}$ bei ausgedehnten Flanerien erkundete, wurde Benjamins " physiognomischer » Blick immer mehr zu einem "politischen Blick», der sich auch auf Umwegen weiterzubilden wußte: z.B. mit Hilfe der Paris-Photographien Emile Atgets, der im Kunstwerkaufsatz von 1936 und noch ausführlicher in der Kleinen Geschichte der 
Photographie als «Tatort» - Photograph gewürdigt wird, als Meister der photographischen Spurensicherung, der in seinen Aufnahmen der leeren Pariser Straßen mit Hilfe von fast unsichtbaren Details zur detektivischen Rekonstruktion der gesellschaftlichen Vergangenheit auffordert. Indem Atget die «stickige Atmosphäre » der herkömmlichen Porträtphotographie «bereinigt » und « desinfiziert ", leitet er darüber hinaus, so Benjamins Sicht, « die Befreiung des Objekts von der Aura » (II.1, 378).

Durch Photographien und Illustrationen aller Art wird sich der mediatisierte Blick auf die Stadt Paris für die Lektüre der realen Stadtlandschaft schärfen, die okkulten städteplanerischen Motivationen durchschauen, die sowohl auf die machtpolitischen Belange der «strategischen Verschönerung » des Präfekts Haussmann als auf Verschiebungen in den Phantasmagorien der kapitalistischen Kultur hindeuten.

11 Einen zweiten mediatisierten Blick wird Benjamin einer Art «Leseflanerie » - der Lektüre von surrealistischen Texten - verdanken. Bücher wie Louis Aragons Le Paysan de Paris und André Bretons Nadja erzählen nämlich nicht nur von geheimnisvollen und zugleich höchst konkreten Topographien, an dem das «surrealistische Gesicht einer Stadt » abgelesen werden konnte, sondern erkunden auch dessen Korrespondenzen mit den Arkanen des Unbewußten ${ }^{15}$ Solche Lektüren sind es, die Benjamin dazu bewegen werden, den «Gegensatz zwischen dem historischen und dem politischen Blick aufs Gewesene » (II.3, 1032) zum Leitprinzip zu erheben.

Im Paysan de Paris stand nämlich schon Entscheidendes über die Beziehungen einer Großstadttopographie zum bildererzeugenden Imaginären des Großstädters, so daß Benjamin sich hier ansatzweise Gedanken über die materiellen und immateriellen Aspekte des im Roman erwähnten "modernen Lichts des Sonderbaren " machen konnte. In einer exzerpierten Stelle des Passagen-Werks wurde das Licht der von Aragon beschriebenen Passagen als "grünlich-trübes ", " abyssales » Licht bezeichnet, das diesen «menschlichen Aquarien » einen zweideutigen Charakter verlieh (V.2, 669). Bei Aragon aber war dieses Zweideutige vorerst keine «bildliche Erscheinung der Dialektik» (V.1, 55), wie bei Benjamin. Es war eine Art mythische Aura, die den Passagen, als « mehrere moderne Mythen in sich bergend[en]» Orten, anhaftete. Im Paysan de Paris werden die Auswirkungen dieser höchst ambivalenten Topographien aufs Imaginäre seitenlang beschrieben. Bestimmte Passagen, wie z.B. die «Passage de l'opéra ", sind in dieser Hinsicht nicht nur « überdachte Galerien », sondern auch " gläserne Särge », die an das ewige Spiel von Liebe und Tod gemahnen ; sie sind auch, gerade an den Stellen, wo sie wieder in eine Straße münden, geheimnisvolle Schwellen, die die ganze Zweideutigkeit des Innens und des Außens dem Passagen-Passanten beinahe als psychologisches Gegensatzpaar (Introvertiertheit / Extravertiertheit) zum Bewußtsein bringen.

Eine derart originelle Annäherung an reale und imaginäre Aspekte der französischen Hauptstadt machte es deshalb Benjamin möglich, deren Passagen mit ihrer unheimlichen Schwellenstruktur zur emblematischen " mythologischen Topographie » der anbrechenden Moderne zu erheben.

Das Häuserlabyrinth der Städte gleicht am hellen Tage dem Bewußtsein; die Passagen (das sind die Galerien, die in ihr vergangenes Dasein führen) münden tagsüber unbemerkt in die Straßen. Nachts unter den dunklen Häusermassen aber tritt ihr kompakteres Dunkel erschreckend heraus und der späte Passant hastet an ihnen vorüber, es sei denn, daß wir ihn zur Reise durch die schmale Gasse ermuntert haben. (V.1, 135) 
Weil die Pariser Passagen als «Erscheinung der Strasse als Interieur, in der die Phantasmagorie des Flaneurs sich zusammenfasst » und "von der Gasbeleuchtung nur schwer zu trennen » sind, wie Benjamin in Das Paris des Second Empire bei Baudelaire schrieb (I.1, 552), konnte er diese Passagen aber auch, wie noch zu zeigen sein wird, auf Aspekte hin untersuchen, die im Wechselspiel von Materialität und Immaterialität, Licht bzw. Beleuchtung, Bewegung und Blick als konstitutiv für die oft betonte «Zweideutigkeit der Passagen $»^{16}$ - innen und außen, Wohnung und Straße, Tag und Nacht, oben und unten - erscheinen ließ : « zweideutige » Lichtverhälnisse, die eine ins Mythische gesteigerte Ambivalenz bewirken, Bewegung des Passagen-Flaneurs, dessen ebenfalls ambivalente Wahrnehmung dem Umstand zu verdanken ist, daß er ständig reale, symbolische und imaginäre Schwellen überschreiten muß, so daß er zum großstädtischen Repräsentanten einer modernen Schwellenkunde avanciert ${ }^{17}$. Hannah Arendt, die in den letzten Pariser Exiljahren zum engeren Freundeskreis Benjamins gehörte, bemerkte dazu :

Und die Passagen sind in der Tat wie ein Symbol dieser Stadt, weil sie offensichtlich Innen und Außen zugleich und damit auf gedrängtestem Raum ihr eigentliches Wesen darstellen. In Paris fühlt sich der Fremde heimisch, weil man diese Stadt bewohnen kann wie sonst nur die eigenen vier Wände. Und wie man eine Wohnung nicht dadurch bewohnt und wohnlich macht, daß man sie benutzt - zum Schlafen, Essen, Arbeiten -, sondern dadurch, daß man sich in ihr aufhält, so bewohnt man eine Stadt dadurch, daß man es sich leistet, ziel- und zwecklos durch die zu flanieren ${ }^{18}$.

15 Was sind aber konkret diese Passagen, die, so Benjamin, als «Abguß eines Traumes » (V.2, 670) und «Urlandschaft der Konsumption» (ebd., S.993) Aufschluß über die Art und Weise geben, wie die frühe hochkapitalistische Warenwelt der Stadt Paris ein neues Stadtbild und Welthauptstadtbild ${ }^{19}$ verlieh und auch später, nach « Hausmanns Zerstörungswerk » $(\mathrm{V} .1,57)$ und nach den spekulationsbedingten Umgestaltungen der Jahrhundertwende, denen viele Passagen zum Opfer fielen, gleichsam als « Denkmäler eines Nicht-mehr-Seins $»^{20}$ (V.2, 1001) eine Lektüre der Urgeschichte des XIX. Jahrhunderts aus der Rückschau ermöglichen? Man kennt Benjamins grundlegende erkenntnistheoretische These : erst in der Stunde des spätkapitalistischen Verfalls, der « Erschütterung der Warenwirtschaft », wie sie nach 1929 weltweit manifest wird, seien die frühen « Monumente der Bourgeoisie » - wie Passagen und Weltausstellungsbauten - « als Ruinen zu erkennen noch ehe sie zerfallen sind » (V.1, 59).

Eine erste Antwort gibt der von Benjamin in seinem Exposé zum Passagen-Werk (Paris, die Hauptstadt des XIX. Jahrhunderts) zitierte Illustrierte Pariser Führer des Jahres 1852 :

Passagen, eine neuere Erfindung des industriellen Luxus, sind glasgedeckte, marmorgetäfelte Gänge durch ganze Häusermassen, deren Besitzer sich zu solchen Spekulationen vereinigt haben. Zu beiden Seiten dieser Gänge, die ihr Licht von oben erhalten, laufen die elegantesten Warenläden hin, so daß eine solche Passage eine Stadt, ja eine Welt im kleinen ist. (V.1, 45)

17 Und Benjamin fügt hinzu: «Die Passagen sind der Schauplatz der ersten Gasbeleuchtung. (ebd.). Das hier angedeutete wesentliche Moment der Beleuchtung hängt aber zunächst mit der neuartigen Architektur zusammen und diese beruht in erster Linie auf der Verwendung neuer Baumaterialien (Eisen und Glas), die zu früh kam und deshalb nicht optimal ausfiel. Darum ist der Tag so schmutzig und trübe, der durch die Scheiben zwischen eisernen Trägern von oben hereinfällt» (V.1, 512). Darüber hinaus verändern diese neuen Eisenkonstruktionen die herkömmliche Beziehung zwischen Innen- und Außenräumen derart, daß deren Wahrnehmung im 
Zeichen einer grundsätzlichen Ambivalenz steht, handelt es sich doch bei den Passagen «nicht wie bei andern Eisenkonstruktionen um Erhellung des Innenraumes, sondern um Dämpfung des Außenraumes » (V.2, 669). Dieses gedämpfte Licht fungiert als eine Art Bühnenbeleuchtung, die für den Besucher- und Käuferblick die Inszenierung der meist hinter gasbeleuchteten Schaufenstern ausgestellten Warenwelt mit einer Aura versieht, wie man ihr auf den frühen Photographien begegnen mochte: es war ein "absolutes Kontinuum von hellstem Licht zu dunkelstem Schatten" als Ausdruck des « technischen Bedingtseins der auratischen Erscheinung 》 (II.1, 376).

Man kann in dieser Hinsicht die zwischen Realem und Imaginärem angesiedelte Bedeutung, die Benjamin den «Beleuchtungsarten» beimaß, nicht hoch genug einschätzen. Im Passagen-Werk hat er ihnen ein ganzes Konvolut gewidmet (V.2, 698f.). Darin spielt das zweideutige Licht par excellence, das Gaslicht der frühen Stadtbeleuchtung, eine herausragende Rolle, wie im Passage du panorama, die als einer der ersten öffentlichen Orte mit Gas beleuchtet wurde :

Passagen - sie strahlten ins Paris der Empirezeit als Feengrotten. Wer 1817 die Passage des Panoramas betrat, dem sangen auf der einen Seite die Sirenen des Gaslichts und gegenüber lockten als ölflammen Odalisken. Mit dem Aufblitzen der elektrischen Lichter verlosch das unbescholtene Leuchten in diesen Gängen, die plötzlich schwieriger zu finden waren, eine schwarze Magie der Tore betrieben, aus blinden Fenstern in sich hineinschauten. (V.1, 700)

In einem exzerpierten Zitat über das Gaslicht aus Egon Friedells Kulturgeschichte der Neuzeit III (1931), das Benjamin rezensiert hatte, ist von « diesem lauten und trüben, scharfen und flackernden, prosaischen und gespentischen Licht » die Rede.

Das Epitheton « trübe », das an Aragons oben zitierte « lueur glauque » der « aquariums humains » anklingt, wird oft mit dem Gaslicht assoziiert. Da dieses aber vor dem später aufgekommenen elektrischen Licht nur "verblaßen » konnte, muß dieses «trübe » relativiert werden, wie Benjamin es in einem frühen abgeschlossenen Text des Passagen-Werks tut :

Wenn für uns heute Gasbeleuchtung manchmal eher einen trübenden beklemmenden Eindruck macht, so stellte sie jenem Zeitalter den Höhepunkt des Luxus und der Feierlichkeit dar. (V.2, 1060).

21 Darüber hinaus ist das in Benjamins Werk öfters vorkommende Gaslicht-Motiv eine Chiffre nicht nur des Zweideutigen, sondern auch des Unheimlichen: in zwei verschiedenen Texten der Berliner Kindheit (« Tiergarten » und «Winterabend ») finden sich folgende Beobachtungen des nächtlichen Berlin : «Das Gas, das auf unser Pflaster schien, warf ein zweideutiges Licht auf diesen Boden » (IV.1 238) - eine Stelle, die sich fast wörtlich in der Hessel-Rezension «Die Wiederkehr des Flaneurs» (III, 194), im «Flaneur» - Kapitel (V.1, 524) und in einem frühen Entwurf des Passagen-Werks wiederfindet (V.2, 1053). Es ist eine regelrechte Verfremdung des Vertrauten, die da stattfindet: "Es war ein dunkles, unbekanntes Berlin, das sich im Gaslicht vor mir ausbreitete " (IV.1, S.288). Und in dem späten Text Über einige Motive bei Baudelaire (1939) erhält die Londoner Menge durch die Gasbeleuchtung eine unheimlich anmutende Aura: sie ist «düster und zerfahren wie das Gaslicht, in dem sie sich bewegt » (I.2, 625).

Das Gaslicht erzeugt aber eine Form der Zweideutigkeit, die in den Passagen, wie ein früher Entwurf von 1929 festhält (V.2, 1049), von einem « äußerlichsten nur ganz peripheren Aspekt der Zweideutigkeit » ergänzt wird, dem die Passagen «ihrem Reichtum an Spiegeln» verdanken. Es ist diese Allgegenwart der Spiegel, die "die 
Räume märchenhaft ausweitet » und "die Orientierung erschwert». Liegt es daran, dass in dieser Vielzahl von Spiegeln eine verfremdende Schwellenkunde steckt? Denn die Spiegel figurieren einen vom Spiegelrahmen abgegrenzten « Außenraum », der das bespiegelte Innen zum Pseudo-Außen verfremdet und eine «Verschränkung der Räume » hervorbringt, einem «Schauspiel, dem der Flaneur unentrinnbar verfallen ist » $(\mathrm{V} .2,666)^{21}$. So gelingt es dem Flanierenden, dessen Blickbewegung gemäß der realen Topographie der Passagen zu einer von Schwenks unterbrochenen Kamerafahrt tendieren dürfte, wegen dieser grundsätzlichen Zweideutigkeit der Räume wahrscheinlich nur mit Mühe sowohl die ausgestellten Gegenstände und deren Rahmen als auch die Mitflanierenden eindeutig in den Blick zu bekommen. Diese Unsicherheit des Blicks, der in der «Spiegelstadt» Paris dennoch lernen muß, sich rasch zurechtzufinden ${ }^{22}$, nimmt vielleicht das vorweg, was später im Film im Spiel zwischen « champ » und « hors champ » zur imaginären Verschränkung der Räume wird, wenn der Bildausschnitt als Dispositiv eines erweiterten Sehens fungiert.

Diese Betrachtungen über die Herausbildung eines perzeptiven Habitus, einer vorkinematographischen « Seh-Kunst » durch das « moderne Licht des Sonderbaren » und die strukturelle Zersplitterung des Blickfeldes in den Passagen, können durch andere ergänzt werden, die nicht mehr dem Zusammenspiel von Beleuchtung und Topographiegelten.

24 Es geht vielmehr darum, aufzuzeigen, wie die geschilderte Verschränkung des «Optischen" und des "Taktilen» in der Großstadtflanerie mit Benjamins Einschätzung der medienästhetischen Bedeutung der kinematographischen Montage aufs engste verknüpft ist. Denn, wenn der Flaneur die Schwelle, wo die Passage in die Straße mündet, nach einigem Zögern überschritten und das Ambivalente einer Topographie hinter sich gelassen hat, in der sich die Straße "als das möblierte ausgewohnte Interieur der Massen zu erkennen» gab, begibt er sich in eine technifizierte Welt, die « das menschliche Sensorium einem Training komplexer Art » unterwirft (V.1, 533). Die Schocks und Kollisionen, denen der Einzelne im modernen Großstadtverkehr ununterbrochen ausgesetzt ist, machen aus ihm, wie der von Benjamin zitierte Baudelaire schreibt, « ein Kaleidoskop, das mit Bewußtsein versehen ist» und die großstädtische Außenwelt als diskontinuierlich, bruchstückhaft und zutiefst unüberschaubar erlebt. Da scheint unweigerlich der Tag kommen zu müssen, «da einem neuen und dringlichen Reizbedürfnis der Film entsprach». Denn, so Benjamin weiter, «im Film kommt die chockförmige Wahrnehmung als formales Prinzip zur Geltung. $»^{23}$

\section{Kleiner Exkurs über die Aura ${ }^{24}$}

Es wäre im Zusammenhang mit den Passagen die licht-bzw. beleuchtungsbedingte Komponente der Aura in aller Deutlichkeit herauszustellen, wie sie die Kleine Geschichte der Photographie am Beispiel der frühen Photos herausgearbeitet hatte, auf denen das Licht sich «mühsam [...] aus dem Dunkel ringt» (II.1, 376). Ansätze zu deren Beschreibung ließen sich unschwer aus der oben zitierten Definition der Passagen im Illustrierten Pariser Führer herausdestillieren, in der eine auratisierende Wirkung der in den Passagen herrschenden Lichtverhältnisse (« Licht von oben », « Gasbeleuchtung ») angedeutet wird: die in den frühen "Tempeln der Ware» zum Kauf angebotenen Gegenstände erhalten eine auratische Dimension (weichgezeichnete Konturen), die 
durch das Zusammenwirken des gedämpft einfallenden Tageslichts und des Gaslichts zustande kommt. Die Waren erhalten eine Art « Kultwert », der sich deutlich von dem im Kunstwerkaufsatz erwähnten abhebt. Denn die Aura der fetischisierten Waren ändert sich mit deren Verlegung ins Warenhaus bzw. in die Riesenhallen der Weltausstellungen, in die die Strombeleuchtung schnell Eingang findet. Die frühe Warenaura der Passagen, der noch Geheimnisvolles anhaftete, wird durch die ostentative Zurschaustellung der ausgestellten Massenware verdrängt. Die « Traumbefangenheit » der phantasmagorisch sich präsentierenden Warenwelt bleibt es findet also kein Funktionswechsel statt -, nur ihr Ausdruck ist ein anderer. Daraus ergibt sich ein ähnlicher Unterschied wie zwischen der "sanften" Aura der frühen Photographien und der schärfer konturierten Aura der neusachlich verklärten Welt der Ware und der Technik ${ }^{25}$.

Die Umstellung der Beleuchtung von Gas auf Strom ist für die Qualität der Aura, zumal der Warenaura, nicht gering einzuschätzen. Denn « solange in ihr [der Passage, A.C.] die Gas- ja die Öllampen gebrannt haben, waren sie Feenpaläste ", schreibt der von Benjamin zitierte Frühsozialist Charles Fourier (V,2, 1001), eine Bezeichnung, an die der ursprünglich vorgesehene Titel des Passagen-Werks (Pariser Passagen. Eine dialektische Feerie) anknüpft. Fourier fügt nostalgisch hinzu: «Der Niedergang beginnt mit der elektrischen Beleuchtung ", als würde die neue Technik - die " fée électricité » - durch die Vertreibung des zweideutigen Gaslichts ${ }^{26}$, die imaginäre Dimension des Wahrgenommenen endgültig verändern. Die Möglichkeit, beide Lichtquellen jedoch zu einer neuen phantasmagorischen Wirkung zu kombinieren, wird in einem Exzerpt aus einem Paris-Buch angedeutet. Darin ist die Rede von einem « Traumdekor, in dem sich das flackernde Gelb der Gasbeleuchtung mit der mondscheinhaften Frigidität des elektrischen Funkens vermählt » (V.2, 698).

Einen Übergang $\mathrm{zu}$ den Panoramen bietet hier eine Stelle aus dem Text « Kaiserpanorama » in Die Berliner Kindheit um 1900, einem Werk, das zwischen 1932 und 1938 - parallel zur Arbeit am Passagen-Werk also - geschrieben wurde. Hier fungiert das Gaslicht wieder als Chiffre der durch die Exilsituation verstärkten Unheimlichkeit erinnerter Kindheitserfahrungen. Während in Benjamins Schilderung der stereoskope Blick durch das «Fensterpaar » zunächst in eine «schwachgetönte Ferne » sah ${ }^{27}$, wird eine Ansicht der französischen Stadt Aix-en-Provence im Berliner Kaiserpanorama zur «Erinnerung an die Zukunft », zur Rückblende, bei der die Gegenwart durchscheint. In der Ambivalenz ihrer Doppelbelichtung ist die Aura hier umgekehrt eher die Erscheinung einer Nähe, so fern sie sein mag, heißt es doch von ihr, « daß ihre ferne Welt nicht immer fremd und daß die Sehnsucht, die sie in mir weckte, nicht immer eine lockende ins Unbekannte, vielmehr bisweilen jene lindere nach einer Rückkehr ins Zuhause war. Das aber ist vielleicht das Werk des Gaslichts gewesen, das so sanft auf alles fiel.» (IV, 1, 240) Genauso wie dieses zweideutige Licht möglicherweise bei dem sich erinnernden Erwachsenen dafür verantwortlich war, daß die im Kaiserpanorama gezeigten Kassetten wie auratische « Aquarien der Ferne und Vergangenheit » wirkten, die wegen der ähnlichen Qualität des Lichts dennoch Reminiszenzen ans nahe Heimische hervorriefen. Denn man «trat ins Innere [des Panoramas, A.C.] und fand nun dort in Fjorden und auf Kokospalmen dasselbe Licht, das abends bei der Schularbeiten [...] das Pult erhellte. »

Die Metapher des « Aquariums » mit seinen trüben, zweideutigen Lichtverhältnissen ist wiederum - über Aragons Paysan de Paris, wie wir gesehen haben - eine Art 
Verbindungschiffre zwischen der Welt der Passagen und der Welt der Panoramen bzw. Dioramen, die « in den Passagen nisteten ». Von diesen als den « innersten glühenden Zellen der ville lumière " heißt es in einem frühen Entwurf des Passagen-Werks : «Es war im allerersten Augenblick als beträte man ein Aquarium. An der Wand des großen verdunkelten Saales zog es sich, von schmalen Gelenken durchbrochen, wie ein Band hinter Glas erleuchteten Wassers entlang. » (V.2, 661)

\section{Panoramen} «panoramatische Blick» von besonderer Bedeutung. Er erscheint zunächst ebenfalls als zweideutig, je nachdem ob er, wie bei einem Filmkameraschwenk, die abgebildete Welt vom Mittelpunkt einer Rotunde aus aufnimmt oder, wie im Kaiserpanorama, von außen durch ein stereoskopes Guckloch ruckartig an sich vorbeigehen läßt. In dieser strukturellen Ambivalenz des panoramatischen Blicks schlagen sich wieder Elemente einer vorkinematographischen Problematik nieder, die mit den kapitalistischen Phantasmagorien des 19. Jahrhunderts eine enge Verbindung eingehen.

Panoramen werden Gemälde genannt, die eine Landschaft oder eine Szene so darstellen, als ob sich der Beschauer mitten darin befindet. Die Leinwand mit dem Bild wurde damals in einem runden Gebäude aufgestellt, das einen Umfang bis zu vierzig Metern Durchmesser besaß, so daß das Rundgemälde den Beschauer häufig von allen Seiten umgab. Die Perspektive des Gemäldes war genau nach dem Standpunkt des Betrachtenden berechnet. In der Mitte der sogenannten Rotunde baute man deshalb eine Art Podium, von dem aus man sich das Panorama anschauen mußte, während es von einem anderen Standpunkt aus gesehen verzerrt erschien $^{28}$.

Solche Panoramenbilder, wie sie während des ganzen 19. Jahrhunderts als streng nach den Gesetzen der Perspektive konstruierte und deshalb illusionsteigernde Abbilder zu sehen waren ${ }^{29}$, - die überdies, wie später bei den meisten Kameraschwenks, eine lineare Kontinuität des Gezeigten vortäuschen -, präsentieren dem Zuschauerblick die abgebildete Wirklichkeit immer als fließenden Zusammenhang ohne Bruch- und Nahtstellen. Wodurch eine Apperzeption erzeugt wird, die glatt und linear verläuft, ohne je an die Grenzen eines Bildrahmens zu stoßen, der zugleich die Schwelle zwischen Abbild und Wirklichkeit materialisieren würde, so daß manchmal zur Vervollkommnung der Inszenierung, d.h. zur Steigerung der Illusion, vor der Leinwand buchstäblich « ins Bild passende » Gegenstände aufgestellt werden konnten ${ }^{30}$. Durch die perspektivische Illusion des Panoptikums, die den stets gleichen Abstand zwischen Beschauer und Beschautem nur im Schein aufhebt ${ }^{31}$, wird der «Blick von einer erhöhten und mit einer Balustrade umgebnen [sic!] Plattform ringsum auf die gegenüber und darunter liegenden Flächen » (V.2, 656), so Benjamins Beschreibung des visuellen Dispositivs, zugleich zu einem allmächtigen und zu einem imaginären. Es ist dies ein perzeptiver Eindruck, der besonders bei den von vielen Panoramenmalern bevorzugten Schlachtenbildern empfunden werden mag: man ist « mitten drin » und kann dennoch alles "mit einem Blick» überblicken, wie von einem zentralen Feldherrnhügel aus, wobei hier bemerkt werden muß, daß jeder wirkliche Feldherr mit Hilfe eines Feldstechers ohne weiteres in der Lage wäre, die « Einstellungsgröße » und die «Tiefenschärfe » beliebig zu variieren. Ein derart entgrenzender Blick, der als Korrelat zum allumfassenden Überblick im Zeitalter der technischen und 
wirtschaftlichen Entgrenzungen gedeutet werden kann, macht jede Montage, wie sie in der Wirklichkeit vorkommen würde, von vornherein unmöglich.

Als Bewunderer der großen Russenfilme, ohne die viele Aspekte seiner späteren Ästhetik nicht denkbar sind, hätte Benjamin die in den Panoramen stattfindende völlige Okkultierung der für ihn wesentlichen «Chockwirkung» kritisieren können, die, wie er befand, dem auf dem Schnitt basierenden Medium Film inhärent war ${ }^{32}$. Nimmt man das Beispiel einer panoramisch überblickten Großstadt, die eine beliebte Panoramenszenerie des von Benjamin erwähnten «großen Panoramenmalers Prevost ", des Lehrers Daguerres, darstellte ${ }^{33}$, so kann festgestellt werden, dass diese den Blick auf seine optische Dimension reduziert, da sie ihm nur die glatte Leinwandoberfläche bietet. Eine solche Stadt wird nicht mehr, wie im realen Straßengedränge, optisch, auditiv und taktil als Summe von "Chockwirkungen " erlebt, ein Umstand, der Benjamins zufolge für die Herausbildung der Perzeptionsweise und folglich der Ästhetik der Moderne von entscheidender Bedeutung war ${ }^{34}$. So wie das in der Wirklickeit permanente "Chockerlebnis» der Schlachtszenen - was jede Schlacht auch für den nur beobachtenden Feldherrn ist - auf einen geglätteten revuemäßigen Rundblick verkürzt wird.

Durch den Wegfall des vielfältigen Schockmoments ${ }^{35}$ wird also eine als solche, durch den Schnitt sichtbar gemachte Fragmentierung und Neuzusammensetzung des Gezeigten verhindert, die für Benjamin erst die Voraussetzungen für eine entauratisierte kollektive Wahrnehmung schafft, wie sie folglich erst in der kinematographischen Form der Wirklichkeitsreproduktion systematisch möglich wurde. Als Architektur und gemalte Bildfläche, implizieren also Panoramen ein besonderes visuelles und sogar körperliches Dispositiv, an dem sich ein Verlust der für Benjamin wesentliche Dimension des Taktilen im Visuellen verdeutlichen läßt, die im Kunstwerkaufsatz Erwähnung fand: "Bauten können auf doppelte Art [rezipiert werden] : durch Gebrauch und durch Wahrnehmung. Oder besser gesagt: taktil und optisch. » (I.2, 465).

Das wichtigste Merkmal der Panoramen, das deren Exemplarität für die « Urgeschichte des 19. Jahrhunderts " sichert, ist aber das Panoptikum, das sich als universelles und universalistisches Sehprinzip sowohl in den Gefängnissen als auch auf den Weltausstellungen etablierte. So mochte auch Benjamin in den Panoramen «eine Erscheinungsform des Gesamtkunstwerks » sehen, in der der Universalismus des 19. Jahrhunderts deshalb sein «Denkmal » hat, weil in Wirklichkeit «Pan-Optikum [...] nicht nur meint, daß man alles sieht ; man sieht es auf alle Weise. » (V.2, 660)

Am Beispiel des von Bentham konzipierten «Panopticons» hat Michel Foucault im panoptischen Sehen eine Art Idealtyp des Totalitarismus des Sehens dingfest machen wollen und dieses neue Sehdispositiv als historisches Kennzeichen einer auf weitgehende Durchleuchtung des Gesellschaftskörpers hinarbeitenden, durchrationalisierten «Disziplinargesellschaft» ausgelegt. Foucaults Ausführungen deuten das für die zentrale (und unsichtbare) Überwachung von Gefängniszellen 1791vorgesehene "Panopticon" als "Sehmaschine " und "Gestalt politischer Technologie, die man von ihrer spezifischen Verwendung ablösen kann und muß». Dessen Prinzip wurde, wie Foucault in einer Fußnote vermerkt, erst vier Jahre nach dem Bau des ersten Panoramas durch R. Barker beschrieben. Foucault schreibt dazu : «Die Besucher nahmen den Platz des souveränen Blicks ein », ein Ausdruck, der hier wörtlich zu nehmen ist («Blick des Souveräns»), da der zentrale Rundblick in den 
Machtdispositiven bzw. Machtinszenierungen früherer Zeiten meistens das optischpolitische Privileg des Herrschers war ${ }^{36}$. Im Unterschied zum Dispositiv der Panoramen macht das «Panopticon » die überwachende Macht - man möchte hier in Anlehnung an den Filmbegriff buchstäblich von einer « Aufsicht » haltenden Macht sprechen - zwar «sichtbar » aber " uneinsehbar ", so daß der beobachtete Gefangene, der nie wissen kann, ob ein Aufseher ständig im Turm sitzt, auch der Gefangene seiner eigenen Verinnerlichung des Machtblicks ist, den er als allgegenwärtig phantasiert. Insofern, so Foucault weiter, ist das Benthamsche Panoptikum eine Maschine zur Scheidung des Paares Sehen/Gesehenwerden ${ }^{37}$.

35 Am panoramatischen Blick sind aber möglicherweise andere Merkmale von größerer Relevanz, die sich an bestimmten «mythologischen Topographien» ablesen lassen: z.B. an der Architektur und der Warenausstellung der großen Pariser Warenhäuser oder der für die Weltausstellungen gebauten Paläste des XIX. Jahrhunderts. Daß die Weltausstellungen, deren bewußtseins- und kulturindustrielle Dimension Benjamin im III. Kapitel des Exposés zum Passagen-Werk kurz umrissen hat - Kapitel II war bezeichnenderweise den Panoramen gewidmet -, als riesige Warenschauen besondere Affinitäten zu den Panoramen hatten, zeigt schon die Tatsache, daß diese auf den Pariser Weltausstellungen bis 1900 anzutreffen waren. Eins davon wurde sogar 1889 in einer im Zentrum der Ausstellung gebauten Rotunde untergebracht.

Wenn der von Benjamin beschriebene warenfetischisiende Kapitalismus die Kauflust zunächst als Schaulust erregen muß, ist eine sinnvolle Lenkung des Käuferblicks im Zeitalter der Massenproduktion am besten durch eine panoptisch gestaltete Ausstellung der Fülle zu erreichen. Deshalb kann Benjamin schreiben, daß die Weltausstellungen «das Universum der Waren aufbauen" (V.1, 51). Im Unterschied zum dominierenden Blick-« Travelling » der flanierenden Käufer in den Passagen ist es für die optische Stimulierung des Massenkäufers zunächst wichtig mit einem schwenkenden, allumfassenden Rundblick das Warenangebot erfassen zu können, bevor er, wie es in einer von Benjamin zitierten Publikation der kaiserlichen Kommission der Weltausstellung von 1867 steht, durch den kreisförmig gebauten Palast seine Runde wie bei einer Reise um die Welt macht, die in diesem Tempel der kapitalistischen Zivilisation durch erlesene Exemplare der weltweiten Warenproduktion vertreten ist (V.1, 238). Deshalb bedeutet die Entwicklung des Passagenmagazins zum Warenhaus, wie Benjamin in einem Zitat festhält, vor allem eins : « Die Stockwerke bilden einen einzigen Raum. Man kann sie "sozusagen mit einem Blick umfassen". » (V.1, 90). An anderer Stelle des Passagen-Werks heißt es : « Spezifika des Warenhauses : die Kunden fühlen sich als Masse ; sie werden mit dem Warenlager konfrontiert ; sie übersehen alle Stockwerke mit einem Blick » (V.1, 108).

37 Kinematographisch ausgedrückt dominiert also in der panoptischen Ordnung der Warenpaläste, im Gegensatz zur Wahrnehmungssituation des Flaneurs in den Straßen der Großstadt, nicht mehr die meist holpernd verlaufende "Kamerafahrt » (wie mit einer auf der Schulter getragenen Kamera ohne «steadycam»), die als Blick des sich bewegenden «Mannes in der Menge» mit dieser «mitfahren» kann. Dort herrscht eher der überschauende Schwenk, so daß der panoramatische Blick nicht zuletzt als visuell besitzergreifender Käuferblick gedeutet werden kann. Daß das an mancher Warenhaus- bzw. Weltausstellungsarchitektur abzulesende Totalitätsphantasma darin bestehen kann, wie Benjamin belegen möchte, die ganze Welt bzw. die ganze menschliche Produktion seit ihren Anfängen an einem weltkugelrunden Ort $\mathrm{zu}$ 
versammeln, rückt diesen wieder in die Nähe der Foucaultschen Problematik der "großen Einschließung " (grand enfermement), die mit dem Aufkommen des visuellen Machtdispositivs des Panoptikums von Bentham in einem symbolischen Zusammenhang stand. Vielleicht wäre also der panoramatische Blick als falsche (Seh) Bewegung aufzufassen, während der taktile Blick des Flaneurs, der nur durch ständige Montage die Wahrnehmungsschocks in der modernen Großstadt zu verarbeiten vermag, eine Blickform darstellt, die jedes (phantasmagorische) Kontinuum aufsprengt und dadurch eine «neue Region des Bewußtseins $»^{38}$ entstehen läßt.

Der ambivalenten «Souveränität» des panoramatischen Blicks im «frühen Hochkapitalismus ", der von einer rasend expandierenden (Waren-) Welt auf phantasmatische Weise Besitz ergreift, setzt Benjamin im schon erwähnten « Kaiserpanorama »- Text der Berliner Kindheit die ebenfalls ambivalente Intimität der kindlichen Schaulust entgegen, in der die Trennung zwischen Innen und Außen, Blick und Körper, Optischem und Auditivem ein ganz anderes Dispositiv des Sehens impliziert. Wie schon erwähnt, sitzen die Zuschauer im Berliner Kaiserpanorama draußen und beobachten durch zwei Gucklöcher die innen gezeigten Bilder, deren Wechsel jeweils von einem Klingelzeichen angekündigt wird : "Das war ein Klingeln, welches wenige Sekunden, eh das Bild ruckweise abzog, um erst eine Lücke und dann das nächste freizugeben, anschlug.» (IV.1, 239). Hier wird der Blick kindlichvoyeuristisch wie von einer $\mathrm{zu}$ erwartenden «Urszene» gefesselt, während das körperlich-taktile Moment der Wahrnehmung zugunsten einer Hypostasierung des Optischen ausgeklammert bleibt. Andererseits wird das Gezeigte nicht mehr in seiner nahtlosen, fließenden Kontinuität wahrgenommen, sondern als Bilderfolge, wobei das Klingelzeichen - ein "eigentlich störender Effekt» - nicht nur den durch den Bildwechsel erzeugten «Schnitt» verstärkt, sondern auch die Trennung zwischen Vergangenheit (das zuletzt gesehene Bild) und Zukunft (das darauffolgende Bild) als bildlose Schwelle einer unsichtbaren aber hörbaren Gegenwart erscheinen läßt ${ }^{39}$. Darüber hinaus durchkreuzt die durch das Klingeln erzeugte «wehmutsvolle Abschiedsstimmung » das Phantasma einer totalen Erfassung der großen weiten Welt. Das Kind Benjamin kam «zur Überzeugung [...], daß es unmöglich sei, die Herrlichkeiten in dieser einen Sitzung auszuschöpfen.» (IV.1, 239)

Man könnte zum Schluß auf einen weiteren vorkinematographischen Aspekt der Panorama-Problematik eingehen, die sich aus Benjamins Analyse des Daguerreschen Dioramas beziehen. Wenn es im zweiten Kapitel von Paris, die Hauptstadt des XIX. Jahrhunderts heißt : « Der Höhepunkt in der Verbreitung der Panoramen fällt mit dem Aufkommen der Passagen zusammen ", bezieht sich Benjamin in erster Linie, wie der Titel des Kapitels («Daguerre oder die Panoramen») besagt, auf die Schauspiele des zweiten Erfinders der Photographie, der als Schüler eines Panoramenmalers debütierte, "dessen Etablissement ", so Benjamin weiter, "sich in dem Passage du Panorama befindet.» (V.1, 48) Nun gilt Daguerre als Betreiber jener besonderen Art von Panorama, die sich Diorama nennt. Ein Unterschied, der in Paris, die Hauptstadt... aber auch im Panorama-Kapitel des Passagen-Werks nicht relevant zu sein scheint, da sich Benjamin in seinen Ausführungen in der Hauptsache für die «Umwälzung im Verhältnis der Kunst zur Technik» (V.1, 48) interessiert, die sich in den gemalten Bildern der Panoramen ankündigt. Befaßt man sich aber mit einem von Benjamin vernachlässigten Aspekt der Dioramenbilder als "Durchscheinbilder», erhält der Konnex Malerei, Photographie und Film einen anderen Stellenwert ${ }^{40}$. 

kann, ist der intendierte Wirklichkeitseffekt der Daguerreschen Bilder nicht so sehr darin zu sehen, daß die Panoramenmaler nach der Natur zeichnen. Es ist vielmehr das besondere Dispositiv der Diorama-Spielart der Panoramen, das in der Lage ist, « in der dargestellten Natur täuschend ähnliche Veränderungen hervorzubringen» und insofern « über die Photographie auf Film und Tonfilm voraus[zuweisen]» $\left(\right.$ V.1, 48 ${ }^{41}$. Benjamin geht auf die Art und Weise, wie diese Veränderungen - "Wechsel der Tageszeit in der Landschaft ", "Heraufziehen des Mondes ", "das Rauschen der Wasserfälle » - technisch erzeugt werden, in seinem Exposé nicht näher ein, wenn er auch im gesammelten Material des Photographie-Konvoluts des Passagen-Werks einen 1937 in der Frankfurter Zeitung erschienen Artikel von Dolf Sternberger zitiert, der die Bildmetamorphosen der Dioramen ausführlich beschreibt ${ }^{42}$. Er hätte sonst schildern können, wie diese Veränderungen, die eine besondere Art von lichterzeugter Bewegung « im Stillstand » darstellen ${ }^{43}$ - als wären sie eine frühe Synthese aus "image-temps » (Zeit-Bild) und "image-mouvement» (Bewegungsbild), in der Terminologie Gilles Deleuzes -, als Licht-Spiele zustande kamen. Denn Daguerre benutzte nicht nur Beleuchtungseffekte, bei denen «schräg einfallendes Tageslicht [...] durch öffnen und Schließen von Läden und Verwendung gefärbter Medien das Bild in allen möglichen Lichtwirkungen erscheinen" ließ, wie Zglinicki das Verfahren beschreibt ${ }^{44}$. Die Veränderungen waren in der 1831 verbesserten Diorama-Version schon auf der beidseitig bemalten Leinwand gleichsam latent vorhanden; die Beleuchtungseffekte dienten, wie bei der photographischen Entwicklung - und hier nimmt der Maler Daguerre ein wesentliches Element seiner späteren Erfindung vorweg -, im wahrsten Sinne als "révélateur», so der französische Terminus für Entwickler (wörtlich « Offenbarungsmittel»). Daguerre konnte, so Zglinicki weiter, «durch Verwendung eines durchscheinenden Stoffes (Shirting) als Malereiuntergrund ein nicht nur in der Beleuchtung, sondern auch inhaltlich verändertes Bild herstellen, indem auf der Rückseite das vordere Bild in den Konturen wiederholt, aber durch zusätzliche Malerei ergänzt wurde. Daguerre beleuchtete dann zunächst die Vorderseite, schloß dann diese vordere Lichtöffnungen und ließ durch Beleuchtung der Rückseite mittels allmählich geöffneter Läden das Bild sich verändern. »

41 In der Filmsprache ausgedrückt, wie Zglinicki und mit ihm andere Kommentatoren es tun, erstrebte Daguerre mit seinem Verfahren eine ähnliche Wirkung wie die späteren kinematographischen Überblendungen, obwohl das erste Bild - und das wäre in Bezug auf die psychischen Dispositive der "Schaulust» kein geringer Unterschied - vom zweiten weniger verdrängt als verändert wurde.

42 Benjamins Anliegen zielte eher darauf $a b$, das Visuelle durch Hinzuziehung von zeitlichen Aspekten zu erweitern. Er rückte den bildverändernden bzw. bilderzeugenden Beleuchtungswechsel in die Nähe der gerafften Zeitdarstellung bei Proust und sah in der strukturellen Ähnlichkeit der Verfahrensweisen in Text und Bild « die niedrigste und die höchste Form der Mimesis » sich die Hand reichen. Insofern, so Benjamin an anderer Stelle des Passagen-Werk-Konvoluts "Panorama», würden die Durchscheinbilder einen «spielerischen Vorläufer des Zeitraffers, eine witzige, etwas böse "tänzerische" Beschleunigung des Zeitverlaufs » figurieren (V.2, 660 u.657).

Man kann hierin eine über das Visuelle erfolgende geschichtsphilosophische Extrapolation am Werk sehen, die dem gegen die "homogene und leere Zeit» gerichteten « historischen Zeitraffer» der Geschichtsthesen (I.2, 701) vorgreifen mag. 
Als könnte in der - zwar technisch komplizierten aber hinsichtlich der Darstellung einfältigen - Zeitraffung der Durchscheinbilder die komplexe Zeit/Bild-Dialektik dieser Thesen, die aus den Grundgedanken des erkenntnistheoretischen Teils des PassagenWerks herauskristallisiert wurden, in nuce enthalten sein. Etwa die grundlegende Einsicht, daß die Beziehung «des Gewesnen zum Jetzt eine dialektische: nicht zeitlicher sondern bildlicher Natur " sei. Daß dagegen Bildliches und Zeitliches, wenn sie der "Realzeit» verhaftet bleiben, nicht so leicht zu trennen sind, darauf sollte vielleicht Benjamins Bezug auf Bretons Betrachtungen in Nadja, der sich in derselben Notiz findet, aufmerksam machen. Dort ist die Rede von einem « Maler, der am späten Nachmittag seine Staffelei vor dem vieux port zu Marseille stehen hat und mit der abnehmenden Beleuchtung die Lichtverhältnisse auf seine(m) (sic!) Bilde immer wieder ändert, bis es die Dunkelheit zeigt. Für Breton aber war es nicht "fertig”. » (V.2, 657).

Um aus der Dunkelheit ein Bild herauszuholen und dadurch nicht nur die Zeit zu "raffen », was an deren linearem Verlauf nichts ändert, bedürfte es, so möchte man metaphorisch schlußfolgern, der naturhaften oder phototechnischen Hilfe eines "Blitzes », damit sich ein wahres Bild einstellt, als « dasjenige, worin das Gewesene mit dem Jetzt blitzhaft zu einer Konstellation zusammentritt » (V.1, 578).

\section{NOTES}

1. Ce texte est celui d'une intervention au colloque «Dispositive des Sehens» qui s'est tenu en octobre 1995 à l'Université de Margurg/Lahn.

2. Vgl. Walter Benjamin: Gesammelte Schriften. Hrsg. Von Rolf Tiedemann und Hermann Schweppenhäuser, Bd.I.2, Bd. II.1, Bd. III, Frankfurt am M. 1974, 1977, 1972. Im Folgenden werden Benjamin-Zitate aus dieser Ausgabe nur durch Angabe von Bandnummer (evtl. Teilnummer) und Seitenzahl belegt.

3. Vgl. Susan Buck-Morss : Dialektik des Sehens. Walter Benjamin und das Passagenwerk. Frankfurt am Main 1989.

4. Vgl. folgende Passagen-Werk-Notiz: "Marx stellt den Kausalzusammenhang zwischen Wirtschaft und Kultur dar. Hier kommt es auf den Ausdruckszusammenhang an. Nicht die wirtschaftliche Entstehung der Kultur sondern den Ausdruck der Wirtschaft in ihrer Kultur darzustellen. Es handelt sich, mit anderen Worten, um den Versuch, einen wirtschaftlichen Prozeß als anschauliches Urphänomen zu erfassen, aus welchem alle Lebenserscheinungen der Passagen (und insoweit des 19. Jahrhunderts) hervorgehen.» (V.1, 573-574).

5. Vgl. Hermann Schweppenhäuser : Ein Physiognom der Dinge. Aspekte des Benjaminschen Denkens, Lüneburg 1992, S.36.

6. Vgl. folgenden Satz aus der «Erkenntniskritischen Vorrede» zum Ursprung des deutschen Trauerspiels: «Indem die Rettung der Phänomene vermittels der Ideen sich vollzieht, vollzieht sich die Darstellung der Ideen im Mittel der Empirie.» (I.1, 214).

7. Vgl. die Thesen «Über den Begriff der Geschichte» (I.2, 702) und das Konvolut N des PassagenWerks, «Erkenntnistheoretisches, Theorie des Fortschritts» (V.1, 588)

8. «Sammler sind Physiognomiker der Dingwelt», schreibt Benjamin im Passagen-Werk (V.1, 274). 
9. Dieses optisch-begriffliche «Lesen» ist bei Benjamin ausdrücklich im ursprünglichen Sinne eines aussondernden Sammelns zu verstehen, das einen ausgeprägten Sinn für «unsinnliche Ähnlichkeiten» haben soll. Vgl. hierzu den in den ersten Monaten des Exils (Sommer 1933) geschriebenen Text Über das mimetische Vermögen (II.1, 210-213), in dem von einem archaischen « Lesen vor aller Sprache» die Rede ist, « aus den Eingeweiden, den Sternen oder Tänzen. Später kamen Vermittlungsglieder eines neuen Lesens, Runen und Hieroglyphen in Gebrauch ». Die Sprache selbst stelle «die höchste Stufe des mimetischen Verhaltens und das vollkommenste Archiv der unsinnlichen Ähnlichkeiten » dar (ebd., S.213).

10. Im Kunstwerkaufsatz wird der Film «als der derzeitig wichtigste Gegenstand jener Lehre von der Wahrnehmung, die bei den Griechen Ästhetik hieß», bezeichnet (I.2, 466.).

11. Vgl. Hildegard Brenner: «Die Lesbarkeit der Bilder. Skizzen zum Passagenentwurf». In: alternative 59/60, Berlin April/Juni 1968, S.48-61.

12. Wie Norbert Bolz schreibt. Vgl. ders./Bernd Witte : Passagen. Walter Benjamins Urgeschichte des XIX. Jahrhunderts. München, 1985, S.15.

13. Vgl. das gleichnamige Buch Sarah Kofmans.

14. Franz Hessel, mit dem Benjamin1927 erste Pariser Aufzeichnungen verfaßt hatte, war der Autor des Buchs Heimliches Berlin (1927). 1929 veröffentlichte Hessel, der seit 1906 längere Aufenthalte in Paris - der «Metropole des Flaneurs» - machte, Spazieren in Berlin, dem Benjamin unter dem Titel «Wiederkehr des Flaneurs» eine wichtige Rezension widmete : darin wird der verfremdete Blick auf Hessels Heimatstadt Berlin (weil teilweise an Paris geschult) herausgestellt. Die Parallelisierung von Spazieren und Lesen ist Hessel und Benjamin gemeinsam und wird in Hessels Essay Von der schwierigen Kunst spazieren zu gehen (erschienen in Die Literarische Welt 1932) in Anlehnung an Aragons Paysan de Paris ausführlicher behandelt. Nicht von ungefähr hat also Benjamin Hessel in seiner Berliner Chronik als «Bauern von Berlin» porträtiert.

15. Dieses buchstäblich «unterschwellige» Element an der Topographie der französischen Hauptstadt, das dem in den städtebaulichen Umgestaltungen der Moderne - von den Passagen bis zu Hausmanns «perspektivischen Durchblicken durch lange Straßenschluchten» (V.1, 56) noch wahrzunehmenden "antikischen Paris» anhaftet, wird in dem Konvolut C des PassagenWerks - «antikisches Paris, Katakomben, démolitions, Untergang von Paris» (ebd., S.133f.) herausgearbeitet, wobei sich Parallelen zum Freudschen Modell des Unbewußten aufdrängen. Dort wird ausführlich dokumentiert, was in Baudelaires Dichtung thematisiert wird : Paris als « eine versunkene Stadt und mehr unterseeisch als unterirdisch» (ebd., S.55). Die «chtonischen Elemente» (ebd.) sind die bedrohliche Kehrseite von «Paris als Göttin» als «Kapitale des Luxus und der Moden» (ebd., S.52) und erinnern daran, daß die französische Hauptstadt «über einem Höhlensystem [steht]» (Metro und Kanalisationen) und daß «dieses große technische Straßenund Röhrensystem [sich] durchkreuzt mit altertümlichen Gewölben, den Kalksteinbrüchen, Grotten, Katakomben, die seit dem frühen Mittelalter Jahrhunderte hindurch gewachsen sind» (ebd. S.137). Dieses Unterirdische, das angesichts des Glanzes der Oberfläche der Verdrängung und der Vergessenheit anheimfällt, stellt zugleich eine Art mythologisches, unterweltliches Labyrinth dar, das mit der (bewußten) Oberflächenstruktur der Stadt auf mysteriöse Weise korreliert. Es kann folglich als «unheimliche» Stadtphysiognomie im Sinne Freuds begriffen werden: «Man zeigte im alten Griechenland Stellen, an denen es in die Unterwelt hinabging. Auch unser waches Dasein ist ein Land, in dem es an verborgenen Stellen in die Unterwelt hinabgeht, voll unscheinbarer Örter, wo die Träume münden.» (ebd., S.135).

16. Es sei an dieser Stelle an die zentrale begriffliche Bedeutung der «Zweideutigkeit» bei Benjamin hingewiesen. "Zweideutigkeit», so schreibt er in Paris, die Hauptstadt des XIX. Jahrhunderts, «ist die bildliche Erscheinung der Dialektik, das Gesetz der Dialektik im Stillstand.» (V.1, 55) - Diese Auffassung wurde von Adorno kritisiert. Er schrieb an Benjamin : «Ich möchte nur noch sagen, daß nicht Zweideutigkeit die Übersetzung der Dialektik ins Bild ist, sondern 
dessen "Spur", die selber durch die Theorie erst durchzudialektisieren ist. » Theodeor W. Adorno, Über Walter Benjamin, Frankfurt a.M. 19902, S.138).

17. Vgl. zur allgemeinen Problematik der Schwellenkunde und der Großstadtmythologie das Kapitel «Raum des Mythos, Schwellenkunde» in dem Buch von Wilfried Menninghaus: Schwellenkunde, Walter Benjamins Passage des Mythos. Frankfurt a.M. 1986, S.26-58.

18. Vgl. Hannah Arendt : «Walter Benjamin. Teil II. In finsteren Zeiten». In : Merkur Jg.22, 1968, H.239, S.210-211. In ihrem Text spricht Arendt, die im «Flaneur die Schlüsselfigur (von Benjamins) Arbeiten» sieht, vom Flanieren als von «der geheimen Gang- und Denkart des neunzehnten Jahrhunderts » (ebd.).

19. Vgl. Benjamins Exzerpt aus dem Passagen-Werk, in dem die im Second Empire vorherrschende Megalomanie betont wird : «Der Kaiser und sein Präfekt wollten Paris nicht nur zur Hauptstadt Frankreichs, sondern der Welt machen.» (V.1, 193).

20. Vgl. folgende Stelle im Passagen-Werk, die Benjamins geschichtsphilosophisch untermauerte Hermeneutik zusammenfaßt : «Vergangen, nicht mehr zu sein arbeitet leidenschaftlich in den Dingen. Dem vertraut der Historiker seine Sache. Er hält sich an diese Kraft und erkennt die Dinge, wie sie [in] einem Augenblick des Nicht-mehr-Seins sind. Solche Denkmäler eines nicht mehr Seins sind Passagen. Und die Kraft die in ihnen arbeitet, ist die Dialektik.» (V.2, 1001).

21. Benjamin zitiert folgende Stelle aus Gutzkows 1842 veröffentlichten Briefen aus Paris : «Durch Spiegelwände, die die rechts und links aufgestellten Waaren reflectiren, erhalten alle diese locale eine künstliche Ausdehnung, beim Lampenschein eine phantastische Größe.» (ebd.).

22. Benjamin schreibt über seine Erfahrungen in Paris (innen und außen) : «Da Tür und Wände von Spiegeln durchbrochen sind, so weiß man weder ein noch aus vor zweifelhafter Helle. Paris ist die Spiegelstadt. Spiegelglatter Asphalt seiner Autostraßen, vor allen bistros gläserne Verschläge. Ein Überfluß von Scheiben und Spiegeln in den Cafés um sie innen heller zu machen und all den winzigen Gehegen und Abteilen, in die Pariser Lokale zerfallen, eine erfreuliche Weite zu geben.» $($ V.2, 666).

23. Alle Zitate aus: Über einige Motive bei Baudelaire (I.2, 630-631). Die emblematische kinematographische Form des Schocks ist für Benjamin bekanntlich die Montage, deren « physische Chockwirkung», wie er im Kunstwerkaufsatz schreibt, hauptsächlich auf «dem Wechsel der Schauplätze und Einstellungen beruht, welche stoßweise auf den Zuschauer eindringen.» (I. 2, 464). - Es sei an dieser Stelle an die spätere, bei Dokumentarfilmern beliebte Aufnahmepraxis erinnert, bei der der Kameramann als «Mann (mit der Kamera) in der Menge» das schockartige taktile Moment am optischen Bild fast «hautnah» aufzufangen versucht. Es braucht in diesem Zusammenhang nicht betont zu werden, daß Benjamins Reflexionen vor dem Hintergrund der Herausbildung neuer Wahrnehmungsmodelle $\mathrm{zu}$ analysieren wären, wie sie vor allem im Großstadtdiskurs der Neuen Sachlichkeit am Beispiel des Verkehrs, der Lichtreklamen, der sich bewegenden oder sich stauenden Massen etc. zum Ausdruck kamen. Vgl. dazu u.a. Helmut Lethen : Verhaltenslehren der Sachlichkeit. Lebensversuche in der Weimarer Republik, Frankfurt a.M. 1993.

24. Grundlegend zur Aura-Problematik: Marlies Stoessel, Aura. Das vergessene Menschliche, München Wien 1983.

25. Vgl. Benjamins Ausführungen über Alfred Renger-Patzschs Photo-Buch Die Welt ist schön (1927) in : Der Autor als Produzent (II.2, 693).

26. Auratisierend wirkt das Gaslicht auch aufgrund dieser physikalisch-immateriellen Zweideutigkeit. Es läßt die sanft beleuchteten Gegenstände zugleich deutlicher und mysteriöser erscheinen, als würden sie dadurch gleichzeitig in den Blick und in die Ferne gerückt werden.

27. Das Kaiserpanorama in der Berliner Passage Unter den Linden, das in zahlreichen anderen deutschen und europäischen Städten Nachfolger hatte, «bietet 12 Betrachtern Platz, die durch je zwei Okulare von hinten beleuchtete Dias mit Raumbildeffekt betrachten können. Während die Betrachter sitzen bleiben, ziehen insgesamt 36 handkolorierte stereoskopische Glas-Dispositive 
[...] auf einer Drehscheibe im Inneren an ihnen vorbei» ; diese Bilderbewegung wurde von einem Uhrwerk gesteuert (Sehsucht. Das Panorama als Massenunterhaltung im 19. Jahrhundert. Frankfurt a.M., Basel 1993, S.283).

28. Vgl. Friedrich von Zglinicki : Die Wiege der Traumfabrik. Berlin 1986, S.29.

29. Es sei hier auf den in Anm. 25 zitierten, materialreichen Ausstellungskatalog der Ausstellung Sehsucht. Das Panorama als Massenunterhaltung im 19. Jahrhundert verwiesen, die 1993 in Bonn stattgefunden hat.

30. In seinem 1938 geschriebenen Buch Panorama oder Ansichten vom 19. Jahrhundert, das Benjamin ein Jahr später rezensiert hatte (vgl. III, 572-579), geht Dolf Sternberger auf die intendierte Okkultierung des Rahmens und der Nahtstellen in den Panoramenbildern, die ein illusionsförderndes Ineindanderfließen bewirken sollte : «Im gemalten Panorama überwog bei weitem die Natur. Eine ringsum künstlich hergestellte Natur, deren nirgends unterbrochene illusionistische Einheit auch die schwächste Andeutung eines Rahmens verbot und den Charakter eines Bildes auf alle nur mögliche Weise zu verleugnen, den sonst selbstverständlichen Abstand des Betrachters vom Gemälde zu verringern oder zu überbrücken forderte. So erscheint es nur konsequent, daß die bemalte Fläche durch plastische Teile im Vordergrund oder gar durch veritable dorthin verbrachte Naturstücke wie Steine, Sträucher oder auch Gerätschaften ergänzt wird.» (zit. nach der 2. Auflage, Frankfurt am Main 1974, S.14; Hervorhebung von mir, A.C.).

31. Marie-Luise Plessen hebt folgende Stelle aus Sternbergers Buch, in der die Aporien der Illusionskunst als eines Realismuswahns offensichtig werden, hervor : «Um

die zahlreichen Figuren in perspektivisch richtiger Größe ins Gemälde einsetzen zu können, maß er [der damals sehr beliebte Historien- und Panoramenmaler Anton von Werner, A.C.] exakt auf der Generalstabskarte die Entfernungen zwischen den verschiedenen Gegenden des Gefechts und seinem eigenen angenommenen Standorte, welcher dann ja auch derjenige der Betrachter des Panoramas sein würde.» (Marie-Luise Plessen: «Der gebannte Augenblick. Die Abbildung von Realität im Panorama des 19. Jahrhunderts ». In : Sehsucht, a.a.O., S.13).

32. Vgl. I.2, 464.

33. «Das erste französische Panorama ist eine Ansicht von Paris, aufgenommen von der Mittelachse des Tuilerien-Schlosses.» (François Robichon: «Die Illusion eines Jahrhunderts Panoramen in Frankreich", in Sehsucht, a.a.O., S. 57.

34. Vgl. dazu Über einige Motive bei Baudelaire (I.2, 629 f.)

35. Wie ein Zeitgenosse berichtet, konnte der Eintritt in die Rotunde wie ein Schock wirken, solange sich der panoramatische Blick auf das visuelle Dispositiv der Panoramen noch nicht eingestellt hatte : «Den ersten Eindruck, den man beim Eintritt in ein Panorama erfährt, ist der von einer riesigen, aber verworrenen Ansicht, deren verschiedene Motive sich alle auf einmal und ungeordnet dem betörten Auge anbieten wollen.» (Sehsucht, a.a. 0, S.57).

36. Bei der Eröffnung des berühmten Berliner Panoramas der Schlacht bei Sedan (A. von Werner) in Gegenwart des Kaisers war für diesen, wie Dolf Sternberger schreibt, "eigens eine kleine Erhöhung der Plattform eingerichtet worden, die sich nach Bedarf langsam drehte und "dem Beschauer, ohne daß er sich zu bemühen brauchte, den Blick nach allen Seiten des Panoramas vermittelte" : ein Umstand, der die Entrückung, vielmehr die Ablösung dieses Betrachters von sich selbst noch mehr zu vervollkommnen geeignet war.» Diese spezielle Vorrichtung, in der sich die «allerhöchste» Position des Kaisers konkretisiert, hebt nur die strukturellen Eigenschaften des Sehdispositivs des Panoramas heraus, das den (metaphorisch zu verstehenden) «souveränen Blick» noch dadurch verstärkt, daß der Maler, so Sternberger weiter, «mit einem Betrachter rechnete, der wie auf dem Feldherrnhügel selbst mit dem Fernglase das dargebotene Bild durchstöbert.» (Sternberger : Panorama oder Ansichten vom 19. Jahrhundert, a.a.O., S.12).

37. Alle Foucault-Zitate aus : Michel Foucault : Überwachen und Strafen. Die Geburt des Gefängnisses, Frankfurt a.M. 1994², S.256f. - Diese grundlegende Eigenschaft des visuellen Machtdispositivs des «Panopticons» wird auch von Benjamin an den Passagen dingfest gemacht, die wie die 
Panoramen fensterlose Häuser sind, mit dem Unterschied, daß die Fenster der umliegenden Wohnung, «die auf sie herabschauen wie Logen [sind], aus denen man in sie hineinsehen, nicht aber aus ihr heraussehen kann.» (V.2, 661).

38. Vgl. folgende Stelle in der 1927 in Die literarische Welt veröffentlichten «Erwiderung an Oskar A.H. Schmitz» : «Wirklich entsteht mit ihm (dem Film) eine neue Region des Bewußtseins [...]. Er ist [...] das einzige Prisma, in welchem dem heutigen Menschen die unmittelbare Umwelt, die Räume, in denen er lebt, seinen Geschäften nachgeht und sich vergnügt, sich faßlich, sinnvoll, passionierend auseinanderlegen. An sich selber sind diese Büros, möblierten Zimmer, Kneipen, Großstadtstraßen, Bahnhöfe und Fabriken häßlich, unfaßlich, hoffnungslos traurig. Vielmehr : sie waren und sie schienen so, bis der Film war. Er hat dann diese ganze Kerkerwelt mit dem Dynamit der Zehntelsekunden gesprengt, so daß nun zwischen ihren weitverstreuten Trümmern wir weite, abenteuerliche Reisen unternehmen [...] Weniger der dauernde Wandel der Bilder als der sprunghafte Wechsel des Standorts bewältigt ein Milieu, daß jeder anderen Erschließung sich entzieht» (II.2, 752) - Die der kinematographischen Montage innewohnende Sprengkraft, als Möglichkeit des Ausbruchs aus der "einschließenden» Welt der sinnlichen Wahrnehmung, eröffnet also der traditionellen, den menschlichen Gesichtskreis einengenden Apperzeption neue Perspektiven. Sie induziert dadurch eine diskontinuierliche Expansion von Bewegung und Raum, die im Endeffekt eine Erweiterung der geistigen Möglichkeiten des Wahrnehmenden bedeutet.

39. Vgl. dazu Benjamins fünfte These "Über den Begriff der Geschichte», in der die Erkennbarkeit des «wahren Bildes der Vergangenheit» an ein flüchtiges Bild gebunden ist, das « vorbeihuscht» (I.2, 695). Hier trifft man wieder auf einen grundlegenden Aspekt des Benjaminschen Denkens : die Verarbeitung von kindlichen Eindrücken und Empfindungen zu « Perzepten » und «Affekten », die letztere den ersteren «entreißen» und sie zu paradigmatischen seelischen und intellektuellen Grunderfahrungen machen.

Vgl. dazu Gilles Deleuze / Felix Guattari : Qu'est-ce que la philosophie ? Paris 1991, S.158.

40. «Das Diorama (griech. : Durchsehen, Durchscheinbild) ist eine malerische Schaustellung, bei der die nach den Tageszeiten wechselnde Beleuchtung durch künstliche Lichteffekte nachgebildet und so die Illusion eines zeitlichen Ablaufs erzeugt wird. Dazu wird ein möglichst durchsichtiger Bildträger (Schirting, geöltes Papier o.ä.) sowohl von der Vorder - wie der Rückseite mit zeitlich versetzten Stadien derselben Ansicht bemalt (meist Tag- und Nachtbeleuchtung). Durch den [...] Übergang von Auflicht zu Durchlicht erscheint für den Betrachter die Illusion eines Tagesablaufs im Zeitraffertempo.» (Sehsucht, a.a.O., S. 194).

41. In einer Notiz des Passagen-Werks hatte Benjamin das in den Bildveränderungen zu beobachtende «Eintreten des zeitlichen Moments» noch als Transzendierung des Gemäldes interpretiert, die nur « auf die Photographie voraus[wies]» (V.2, 844).

42. Vgl. Sternberger, Panorama oder Ansichten vom 19. Jahrhundert, a.a.O., S.202-203. Hier wäre außerdem anzumerken, daß im Kaiserpanorama, wie es Benjamin wissen mußte, die Beleuchtung reguliert werden konnte, «um verschiedene Tag- und Nachteffekte zu erzielen». (Zglinicki, Der Weg des Films, a.a.O., S.87).

43. Diese Anspielung auf einen der zentralen Begriffe Benjamins («Dialektik im Stillstand») ist hier in einer kinematographischen Dimension zu verstehen.

44. Alle weiteren Zglinicki-Zitate aus : Der Weg des Films, a.a.O., S.102. 


\section{RÉSUMÉS}

In diesem Text wird versucht, Teile der Begrifflichkeit Walter Benjamins mit dessen Analyse des neuen Sehhabitus' der Moderne und seiner Bedeutung für die Herausbildung einer neuen Medienästhetik zu artikulieren. Der Titel seines unvollendeten Hauptwerkes («Passagen») ist als apperzeptive, ideologische oder technologische Übergangs - und Schwellenkunde auf mehreren Sinnebenen $\mathrm{zu}$ verstehen: z.B. als Übergang einer (visuellen und taktilen) Apperzeption, wie sie dem Großstadt-Flaneur eigen ist, zum mehr panoramischen Blick des Besuchers von Weltausstellungen oder des Käufers, der sich in der sehr visuell angelegten Architektur der großen Warenhäuser bewegt oder die damals sehr beliebten Panoramen besucht. Oder als Übergang zu einer vorkinematographischen Technik (Travellings, Schwenks, Montage). Oder als Übergang vom Gaslicht zum elektrischen Licht, das für die ästhetisch-ideologischen Reflexionen Benjamins über die « Aura » nicht ohne Konsequenzen war.

Die Moderne mehrschichtig zu denken - im zusammenhängenden Wandel von kapitalistischer Warengesellschaft, perzeptivem und ideologischem Habitus - macht die Schaffung neuer Begriffe erforderlich. Diese sollen diejenigen « Perzepte » und " Affekte » verschieben und verdichten, die den verschiedenen Dispositiven des Sehens inhärent sind, wie man sie in den realen und imaginären Großstadttopographien der Moderne entdecken kann.

Ce texte se propose d'examiner dans quelle mesure la philosophie de Walter Benjamin peut en partie s'articuler sur ses analyses des différents modes de visualité nés avec la modernité et de leur importance pour une nouvelle esthétique des médias. Le titre du grand œuvre inachevé des Passages opère à plusieurs niveaux de sens comme art du franchissement de seuils perceptifs, idéologiques et technologiques: par exemple, passage de la perception (visuelle et tactile) inhérente à la flanerie urbaine, à la vision panoramique du visiteur des expositions mondiales ou de l'acheteur circulant dans les architectures hautement visuelles des premiers grands magasins, passage de l'habitus visuel déterminé par les nouvelles topographies urbaines à une technique qui sera celle du cinéma (travellings, panoramiques, montage). Ou encore passage de la lumière au gaz à la lumière électrique avec les conséquences qui en découlent pour la réflexion esthéticoidéologique benjaminienne sur l'« aura ».

Penser la modernité sous l'aspect conjoint de l'évolution des matérialités de la société marchande capitaliste et des habitus perceptifs et idéologiques, implique ainsi le recours à une conceptualité qui condense et déplace les "percepts " et "affects» à l'œuvre dans les dispositifs visuels multiples qu'offrent au regard et à la pensée les grandes topographies réelles et imaginaires de la modernité urbaine.

\section{AUTEUR}

\section{ANDRÉ COMBES}

Université de Toulouse 2-Le Mirail 